\title{
O SURGIMENTO E A EVOLUÇÃO DO ENSINO CIENTÍFICO DO DIREITO TRIBUTÁRIO NO BRASIL
}

\author{
Ruy Barbosa Nogueira \\ Professor Catedrático aposentado da Faculdade de Direito \\ da Universidade de São Paulo
}

Em 1936, aos dezesseis anos de idade, portanto há 65 anos, fomos encarregado de dirigir o então Departamento de Impostos da Federação das Indústrias do Estado de São Paulo, recém-fundada e presidida pelo engenheiro, mais tarde senador, Roberto Simonsen. Nenhuma Faculdade de Direito no Brasil ensinava a disciplina Direito Tributário.

Funcionários da Fazenda, guarda-livros e despachantes cuidavam empiricamente dessa matéria fazendária. Falava-se em "Direito Fiscal" mas os estudos eram apenas de legislação, tanto que a melhor publicação existente era a Revista Fiscal e de Legislação de Fazenda, de Tito Rezende, sem dúvida, então o maior estudioso dessa legislação que, por sua conduta ilibada e competência como representante da Fazenda junto ao Conselho de Contribuintes e seus comentários sobre essa mesma legislação, foi inscrito no Livro do Mérito Nacional como o "maior analista das Leis Fiscais"

Em razão do grande atendimento das questões fiscais que exercíamos naquele Departamento de Impostos, como também pelo estudo da legislação fiscal e relacionamento com Tito Rezende, com o qual fundamos a Revista Fiscal de São Paulo, já antes de ingressarmos para a Faculdade de Direito da Universidade de São Paulo, vínhamos praticando intensa atividade no campo dessa legislação, e mesmo já defendendo causas fiscais até chegar ao Tribunal de Impostos e Taxas do Estado de São Paulo, porque, apesar da denominação de Tribunal, este era e é órgão administrativo, do qual, mais tarde, viemos a ser juiz representante dos contribuintes.

Como já vimos, àquela época não-só não havia, no Brasil, o ensino jurídico-tributário mas, por isso mesmo, praticamente não existia a respectiva literatura científica nacional nem estrangeira. Na verdade, só havia legislação e comentários sobre essa legislação.

Acontece ainda que durante a Segunda Guerra Mundial, dentre outros mestres do Direito, perseguidos pelo nazifascismo, vieram a se asilar em São Paulo o genial professor catedrático de Direito Comercial da Universidade de Bolonha, Tullio Ascarelli, ex-discípulo amado do famoso professor Cesare Vivante e também profundo conhecedor do Direito Tributário e, ainda, Heinrich Reinach, fundador, em 1922, da até hoje melhor revista jurídico-tributária da Alemanha, chamada Imposto e Economia (Steur und Wirtschaft), como também ex-advogado perante a Suprema Corte Fiscal da Alemanha (Bundesfinanzhof), Corte esta até hoje com sede em Munique. 
Naquele tempo, mais acentuadamente na área federal, havia a chamada "indústria da multa", que era a absurda e injusta participação direta dos Agentes Fiscais no resultado, não-só da arrecadação dos tributos, mas, também, das multas, contra cujo regime os contribuintes, por meio de suas associações de classe e mais acentuadamente por meio da Federação das Indústrias do Estado de São Paulo, tanto combatiam.

Ao chegar ao Brasil, em outubro de 1940, Tullio Ascarelli, na Federação das Indústrias encarregou-se de estudar e apresentar trabalho sobre essa questão que era verdadeiro flagelo para os contribuintes. Ascarelli elaborou e a Federação publicou seu trabalho sob o título "Quota-parte dos Funcionários nas Multas e os Principios da Justiça Fiscal" trabalho este em que, como jurista da relação entre Economia e Direito, demonstrou também ser profundo conhecedor do Direito Tributário, além de poliglota e comparatista.

Em 1951, já como advogado do Departamento Jurídico da Federação, ampliamos esses trabalhos e novamente aquela entidade, por meio da publicação "Multas Fiscais" renovou este combate que já atingia âmbito nacional.

Estes trabalhos, sem dúvida, influíram na consciência nacional, de tal modo que pela Emenda Constitucional n. 1, de 1969, com redação da Emenda 7, aquela participação foi assim proibida:

\section{“Art.196. É vedada a participação de servidores públicos no produto de arrecadação de tributos e multas."}

Todos podem imaginar como esse medieval e singular sistema fiscal no Brasil, de participação direta dos agentes fiscais autuantes, no resultado da arrecadação de tributos e multas era nocivo e acarretava exacerbações, corrupções e muitas injustiças, pois era incompativel com o poder de acusações, autuações e imposições de multas daqueles mesmos funcionários fiscais, delas beneficiários e que ainda participavam dos próprios órgãos administrativos de julgamento.

Estamos mencionando o nome do professor Tullio Ascarelli, porque queremos homenageá-lo e mostrar como seu ex-aluno, que além de ele lecionar Direito Comercial em curso curricular, por vários anos, na Faculdade de Direito da Universidade de São Paulo, foi quem dedicadamente despertou os estudantes e advogados brasileiros para o estudo científico e aprofundado do Direito Tributário, inclusive do Direito Tributário Comparado.

Mesmo nesta segunda fase, ainda eram poucos os advogados que se interessavam pelos estudos do Direito Financeiro e do Tributário, porque as Faculdades de Direito ainda não os ensinavam. Na prática, e em geral, somente cuidavam desses ramos, mais por dever de oficio, os juristas da Fazenda, das associações de classe e advogados orientadores de empresas. Realmente ainda não havia no País estudos curriculares, sistemáticos ou metódicos, com preocupações verdadeiramente científicas e por isso mesmo, como já citamos, praticamente não havia livros de doutrina nacional nem era conhecida entre nós a vasta literatura estrangeira. 
Foi por isso que procuramos ressaltar, em monografia de 1979: " $A$ contribuição de Tullio Ascarelli para a formação da doutrina jurídico-tributária no Brasil' Trabalho este que também foi publicado na Itália.

Cabe neste ponto esclarecer que, em 1947, foi Tullio Ascarelli o primeiro a lecionar, em nível de pós-graduação, um curso sobre Direito Tributário na Escola Livre de Sociologia e Política de São Paulo, curso este que despertou grande interesse de muitos advogados, dentre os quais também fomos aluno ao lado de Rubens Gomes de Sousa, como de nosso saudoso professor de alemão e de Direito Tributário Germânico, Heinrich Reinach, com o qual e mais colegas publicamos em folhas substituíveis e como novidade no Brasil, por vários anos, a Coletânea "LIFT-Legislação e Jurisprudência Fiscal e Trabalhista". Reinach, que também muito contribuiu para o estudo da Ciência do Direito Tributário entre nós, especialmente em relação à grande literatura jurídico-tributária em língua alemã, viveu e morreu no Brasil.

Acontece ainda, que a partir do quarto ano, como solicitador acadêmico, tive a ventura de instalar com o Mestre Tullio Ascarelli e colegas, escritório de advocacia; no qual a maior prática e estudos eram sobre o campo do Direito Tributário. O professor Ascarelli, além do seu profundo ensino na Faculdade, ainda no escritório nos incentivava a estudar idiomas e nos indicava os melhores livros da literatura estrangeira sobre a tributaristica.

Durante todo o curso de Direito Comercial, em todas as oportunidades relevantes o professor esclarecia aspectos científicos do Direito Tributário e suas relações com o Direito Comercial e acentuava a necessidade de a Faculdade criar a disciplina Direito Tributário.

Parece que seguimos fielmente as suas recomendações, pois a convite de várias organizações sem fins lucrativos, começamos antes do ensino universitário a dar vários cursos anteriores e, afinal, após os concursos, lecionar durante quarenta anos precisamente nos dois primeiros cursos universitários, até nossa aposentadoria aos setenta anos.

Brandão Machado, jurisconsulto, filólogo, comparatista e nosso companheiro de estudos tributaristas, referindo-se ao fato de termos sido aluno e companheiro de escritório, por vários anos, do Prof. Tullio Ascarelli salienta:

"Grande conhecedor do direito tributário, além de eximio comercialista, Ascarelli, como se sabe, tem o mérito de haver introduzido no Brasil a metodologia do estudo científico desse novo ramo do Direito"

Em seguida, referindo-se a nossos trabalhos sobre imposto de consumo, quando advogado-chefe da Federação, conclui:

I. Ruy Barbosa Nogucira, cdição do IBDT/USP, São Paulo, 1979 c publicado na ltália, pcla Editora Ccdam, Padova, 1981, sob o titulo "Il Contributo di Tullio Ascarclli alla Formazione della Dottrina Giuridico-Tributária del Brasile", Diritto c Pratica Tributária, v. III, n. 3. Mais adiante cssa monogratia vai publicada na integra. 
"Tornou-se Ruy Barbosa Nogueira, desde logo, o maior conhecedor da matéria no Brasil, embora também versasse, com a mesma amplitude, todos os temas do Direito Tributário. Ao tempo em que a Universidade não tinha ainda uma cadeira para o ensino da disciplina, ensinou Direito Tributário a gerações e gerações, contribuindo poderosamente com as suas lições na escola, com os seus estudos doutrinários, pareceres e arrazoados, para a formação científica desse novo ramo juridico. ${ }^{2}$

O saudoso Rubens Gomes de Sousa, que foi por quatorze anos professor contratado de Legislação Tributária, na Faculdade de Economia da Universidade de São Paulo, e por trinta anos nosso amigo e companheiro de estudos, também muito privou com o mestre, tendo escrito que recebeu do professor Tullio Ascarelli, "desde a indicação de bibliografia antes desconhecida no Brasil, até a orientação doutrinária e alargamento de horizontes, muito além do campo estritamente tributário"

Durante muitos anos, também tivemos a felicidade de privar com Tito Rezende e colaborar em sua tradicional revista, chegando mesmo, com ele, a fundar a Revista Fiscal de São Paulo que foi editada de 1950 a 1952. Tivemos, ainda, a satisfação de lhe apresentar o professor Ascarelli e muitas vezes, juntamente com Rubens Gomes de Sousa, Gilberto de Ulhôa Canto e outros, promovíamos encontros e discussões sobre a literatura tributária do Exterior.

Despertada assim a necessidade de extensão e aprofundamento desses estudos - que melhor poderiam ser alcançados por meio de efetivo intercâmbio com os cientistas do Direito Financeiro e Tributário de países cultos - é que sobreveio a criação, no Brasil, do Instituto Brasileiro de Direito Financeiro, filiado à International Fiscal Association - IFA, até hoje a máxima entidade desses estudos, com sede em Haia e Amsterdã, Holanda.

Gilberto de Ulhôa Canto, Rubens Gomes de Sousa, Tito Rezende e Paulo Martins, unidos por tais preocupações comuns, promoveram reuniões com mais seis colegas de São Paulo e Rio: Fernando Rudge Leite, Ruy Barbosa Nogueira, Elmano Cruz, Carlos Medeiros Silva, Erymá Carneiro e Abelardo da Cunha, todos membros da IFA, fomos os fundadores do IBDF (hoje ABDF), cujo primeiro presidente foi Tito Resende, após Gilberto de Ulhôa Canto e atualmente é o conhecido tributarista Condorcet Rezende (este, sobrinho de Tito Rezende e ex-companheiro de escritório de Ulhôa Canto) e que com muita competência e extrema dedicação continua as mesmas intenções dos fundadores.

Não podemos deixar de destacar, neste ponto, o texto do Estatuto da ABDF que descreve seus objetivos com a preocupação de incentivar o estudo e o intercâmbio internacional, tanto para fins científicos, como práticos, do comparatismo:

2. Direito Tributário, Estudos em homenagem ao Prof. Ruy Barbosa Nogucira, Saraiva, S. Paulo, 984, pp. XII. 
"Art. $3^{\circ}$ - Constituem o objeto do instituto o estudo do direito tributário internacional e comparado, e da ciência das finanças principalmente;" a. colaborando com a International Fiscal Association - IFA., arregimentando membros comuns, a ela e ao próprio instituto;

b. promovendo e estimulando estudos sobre temas de direito tributário, financeiro e economia, por todos os meios adequados;

c. promovendo a difusão e trabalhos e obtenção de dados e elementos da natureza dos aludidos na letra $b$, anterior;

d. preparando e colaborando na preparação de conferências e congressos, inclusive internacionais, estes de acordo com a IFA;

e. colaborando com o International Bureau of Fiscal Documentation.

Passemos, pois, a um rápido exame da relevância do estudo do Direito Tributário Comparado e especialmente à comprovação experiente da pesquisa e utilização do comparatismo doutrinário, legislativo e jurisprudencial, dentro da globalidade do Direito.

Direito Comparado.

O mestre Tullio Ascarelli, com os recursos de sua genialidade e a extensão de sua cultura, escreveu quando no Brasil verdadeira monografia sob o título "Premissas ao Estudo do Direito Comparado" 3 Como se sabe, atualmente a literatura mundial específica sobre o estudo do Direito Comparado, quer como ciência, quer como método prático comparativo, é bastante extensa.

Para não citarmos muitas obras de Direito Tributário Comparado basta o grande e notável Dicionário do Direito Tributário e das Ciências Fiscais na Alemanha (Handwörterbuch Des Steuerrechts Und Der Steurwissenschten, C. H. BECK, München, 1972 e 2a edição em 1981, em 2 volumes, tamanho enciclopédia, com 1756 páginas. Dentre as recensões dos mestres da tributarística alemã, consta a nossa sob o título:

Prof. Ruy Barbosa Nogueira in einer

Veröffentlichung der Rechtswissenschaftlichen

Fakultät der Universität von São Paulo

O que devemos ressaltar é que a pesquisa de Direito Comparado nem sempre é fácil, pois sendo muitas as línguas (segundo estatísticas de estudos filológicos da Academia Francesa de Letras, até onde puderam excluir os dialetos, temos na terra

3. Esclarecendo $\mathrm{cm}$ nota de rodapé que este cstudo foi realizado c publicado no Brasil, c vertido para o ltaliano com algumas altcrações c adaptações c publicado quatro anos depois na ltália. Vide "Premesise allo studio del Diritto Comparato", de pp. 3 a 38, in SAGGI GIURIDICE, Dolt. A. Giuffré - Editorc, Milano, 1949. 
entre 2 mil e 2,5 mil idiomas gramaticais) e, apesar dos avanços no campo da tradução, inclusive da informática jurídica e da Internet, nem todos os textos de Jurisprudência, legislação e mesmo da melhor doutrina são traduzidos. Portanto, o jurista tem de se cingir a limitado número de países, dos chamados grandes sistemas jurídicos quando faz comparação de sistemas e, talvez mais ainda, quando se utiliza do método comparativo, pois este exige maior proximidade ou parentesco das estruturas normativas comparandas.

Ainda em relação ao comparatismo no campo tributário, Lucien Mehl, no seu compêndio "Science et Tchnique Fiscales" v. 2, pp. 591, ensina que:

"O estudo do direito fiscal estrangeiro pode ser conduzido de duas maneiras.

A primeira abordagem, a mais simples, é o estudo por país. Permite obter uma vista de conjunto do sistema de um determinado pais, distinguir as relações entre seus elementos, ressaltar seus traços gerais, descobrir as ligações entre o sistema fiscal e a estrutura econômica, social e politica.

A outra abord́agem é uma ilustração ou utilização do método comparativo em direito. Este consiste em estudar em relação a cada tributo, e mesmo em relação a cada elemento do tributo (matéria tributável, fato gerador, sujeito passivo, etc.). as definições e as regras aplicáveis em cada um dos paises considerados no cotejo, para fazer ressaltar suas semelhanças e as suas divergências"

Nos estreitos limites de uma palestra, naturalmente o que podemos fazer, em relação ao método comparativo em Direito, é sintetizar algumas das principais funções desse método e assim, mais uma vez, com os ensinamentos do mestre Ascarelli ressaltar que o direito comparado:

1. É um meio de ampliar nossa experiência juridica no espaço. É um meio semelhante ao que a História representa no tempo;

2. Permite-nos, através do enriquecimento da experiência, entender e avaliar melhor os diversos sistemas;

3. Reconstruir os traços fundamentais do Direito na civilização atual ou em determinada época histórica e as linhas básicas do seu desenvolvimento;

4. Auxilia-nos a compreender as relações entre as normas jurídicas e a subjacente realidade social;

5. Dá-nos as razões das diferenças jurídicas;

6. Traz-nos a modéstia e a tolerância que decorrem da ampliação da experiência;

7. Constitui auxílio indispensável para o progresso jurídico dos diversos países, porque oferece a possibilidade de cada um se utilizar das experiências alheias;

8. Na prática auxilia não só a examinar, mas a resolver as questões freqüentes em que, em cada sistema jurídico, exigem a aplicação da lei estrangeira; 
9. Contribui muito para a organização das relações econômicas de natureza internacional;

10. Constitui ainda o Direito Comparado eficiente meio para desenvolver a terminologia jurídica internacional, porque fortalece e desenvolve no direito uma linguagem ideal, internacionalmente uniforme, contribuindo para a maior compreensão, cooperação e unificação internacional.

Em palestra que fizemos na Alemanha, a convite do mestre do Direito Internacional Tributário, e nosso saudoso consócio da IFA, Ottmar Bühler, então presidente da seção alemã da International Fiscal Association - IFA, com sede em Munique, Alemanha, sob o título "Ubersicht Uber das brasilianische Steuerrecht und die deustche Formulierung" "Panorama do Direito Tributário Brasileiro e as Elaborações Germânicas", deste contexto queremos ressaltar em português o seguinte trecho:

\begin{abstract}
"Dando-se a conhecer, a todos os povos, mutuamente, os diferentes sistemas tributários nacionais, poderão eles, ressalvados interesses peculiares, ir aperfeiçoando, harmonizando e universalizando os principios fundamentais de seus sistemas, de modo que se possam ir eliminando os conflitos e os excessos de tributação.

Afinal, têm todos os povos o maior interesse no intercâmbio comercial $e$, este, não deve ser prejudicado por conflitos de formalismos, ou por conflitos de tributações, decorrentes da falta de coordenação dos diferentes sistemas nacionais.

Essa importante tarefa de harmonização, já não apenas dentro de cada sistema tributário nacional, mas dos sistemas nacionais entre si, é, talvez, o maior reclamo que o mundo está fazendo aos juristas do direito tributário.

Além disso, estando a tributação diretamente ligada a atividades econômicas, precisam os juristas dispor de fontes de informações, para bem orientarem a aplicação de capitais e, nesse setor, encontram-se especialmente os países novos que, como o Brasil, dispõe de fontes ainda inexploradas.
\end{abstract}

Eis porque o conhecimento do sistema tributário de cada pais é atualmente assunto de grande interesse e da maior relevância"

Para podermos dar conta do quanto no estudo, no ensino, na consultoria ou no exercício advocatício do Direito Tributário temos podido nos servir do auxilio do comparatismo com grande utilidade, podemos lembrar que já há 54 anos nos servíamos em várias questões como estão referidas nư trabalho que publicamos na Revista de Direito Administrativo, v. XVI, sobre os "Problemas do Imposto de Consumo", em que, para conceituar o significado e alcance da palavra "artefato" dentro da legislação, do imposto de consumo, fomos ao Direito Comparado e 
encontramos verdadeira qualificação jurisprudencial sedimentada em acórdãos da Suprema Corte dos EUA: Esta conceituação veio a ser citada e aceita em vários acórdãos do Conselho de Contribuintes.

Quanto ao ensino universitário, peço licença para dizer que há quase cinqüenta anos, com aprovação da Congregação da Faculdade de Direito da Pontifícia Universidade Católica de São Paulo - PUC/SP, inauguramos o primeiro curso curricular de Direito Tributário, que lecionamos durante quatorze anos, cujo curso prossegue até hoje.

A Pontificia Universidade Católica de São Paulo PUC/SP criou em 1963, a primeira cátedra de Direito Tributário. Após concurso de títulos e provas, obtivemos a livre-docência e em seguida a Cátedra de Direito Tributário, tendo lecionado quatorze anos na Pontificia a matéria específica Direito Tributário e vinte e seis na Faculdade de Direito da Universidade de São Paulo, tendo completado quarenta anos desse ensino até nossa aposentadoria aos setenta.

Esta Faculdade do Largo de São Francisco incluiu no quarto ano a disciplina Direito Tributário. Em seguida, com a "departamentalização" organizou o quinto ano em especialidades e dentro do Direito Empresarial entre outras matérias incluiu a disciplina Direito Tributário Aplicado, cujo ensino pelo método de casos e problemas fiscais foi uma necessidade que estudamos nos EUA, na Columbia University, Nova York.

No curso de pós-graduação, nos graus de mestrado e doutorado, desde 1971, a USP criou o estudo específico do Direito Tributário Comparado, tal é a posição de cúpula e interesse do comparatismo. Recentemente esta Faculdade ainda incluiu no curso de pós-graduação a disciplina Direito Tributário Internacional. Para ingresso na pós-graduação da Faculdade de Direito da USP, é pré-requisito o conhecimento de uma língua estrangeira para o mestrado e para o doutorado duas, entre italiano, francês, inglês ou alemão. Não-só lecionamos, com auxílio de assistentes, todas essas matérias, como escrevemos e publicamos os livros para os respectivos níveis.

Junto à cátedra, fundamos com colegas, há cerca de trinta anos, o Instituto Brasileiro de Direito Tributário IBDT, que é uma entidade sem fins lucrativos e complementar à USP. Desde sua fundação este Instituto vem realizando as Mesas Semanais de Debates Tributários, com grande freqüência, tendo até hoje realizado cerca de mil sessões desses estudos que prosseguem. Cada sessão tem a duração de duas horas, (das 8 h00 às 10h00) e sempre são realizadas toda quinta-feira, na própria Faculdade.

O IBDT publica anualmente a coletânea Direito Tributário Atual, que já chegou a quinze volumes, com trabalhos nossos e de seus associados, e com distribuição gratuita aos sócios e a bibliotecas.

Desde sua fundação, esta entidade também realiza, anualmente, cursos de extensão universitária no Salão Nobre, com surpreendente freqüência, pois neste salão com mil lugares, às vezes as inscrições chegam a atingir seiscentos alunos do Estado de São Paulo, como também de outros estados do Brasil. 
O Instituto, além de sócios fundadores e contribuintes, também tem ainda sócios "honorários" entre os maiores mestres do Brasil e do Exterior, os quais têm colaborado, especialmente nas obras de homenagens que, como obras contendo monografias aprofundadas, têm vindo enriquecer a literatura jurídico-tributária do País.

Neste sentido, apenas como demonstração de intercâmbio internacional já conquistados pelo Instituto, queremos citas os seguintes exemplos:

Na obra monumental e mais completa que já se escreveu no campo da tributarística mundial que é, sem dúvida, "A Ordenação do Direito Tributário" (Die Steuerrchtsordnung), em três amplos volumes, edição Schmidt, Köln, 1993, de autoria do professor emérito Klaus Tipke, de Colonia, Alemanha. À página 64, diz Sua Excelência que a influência do Direito Tributário Alemão tem sido maior na Espanha, Brasil e Japão, e ainda menciona que os membros do Instituto Brasileiro de Direito Tributário em São Paulo traduziram para o português o "Novo Código Tributário Alemão", Rio/São Paulo, Forense, 1978; mais ainda, que vários professores de Direito Tributário da Alemanha são sócios honorários do IBDT, em São Paulo.

Também no magnífico livro em homenagem (Festschrift) ao professor Hugo von Wallis, o qual, além de professor e autor, foi durante oito anos presidente da Suprema Corte Tributária da Alemanha, em Munique. O autor do prefácio ressalta entre os títulos do homenageado:

\section{"Um reconhecimento altamente honroso de sua produção científica deve ser visto na sua nomeação como sócio honoris causa do Instituto Brasileiro de Direito Tributário, em São Paulo" "}

Como se sabe, no mais elevado nivel é um excelente hábito cultural, muito acentuado na Alemanha, a elaboração de livros de homenagem, lá chamados Festschriften, e que tanto contribuem para enriquecer a literatura e aprofundar os temas mediante monografias dos maiores autores.

Além de o Direito Tributário atualmente contar no Brasil com amplo ensino universitário, recentes institutos científicos e escritores de renome, foi idéia dos membros da Mesa Semanal de Debates, em 1974, sob nossa presidência e coordenação, a elaboração do primeiro "Festschrift" "Estudos Tributários", em homenagem à memória de Rubens Gomes de Sousa, Editora Resenha Tributária, São Paulo, 1974, com 514 páginas.

Em 1984, por motivo de completarmos quarenta anos de ensino e trabalho, nosso querido companheiro de fundação do IBDT, o eminente jurista, comparatista e filólogo, Brandão Machado, traduziu os temas de autoria dos maiores

4. Der Bundesfinanzhof und seine Rechtsprechung Grundfragen - Grundlagen - Festschrift für Hugo von Wallis (Editora, STV, Bonn, 1985, pág. 181). Do professor c ministro-presidente von Wallis, pelo IBDT c co-cdição Rescuha Tributária foi publicado $\mathrm{cm} 1981$, um livro de 190 páginas, sob o título "/mposto de Renda", cm portuguĉs, com trabalhos do professor Ruy Barbosa Nogucira c do professor Paulo Roberto Cabral Nogueira, scndo cnviados mil exemplares, gratuitamentc, aos sócios do IBDT. 
tríbutaristas da Europa e das Américas e ainda com a colaboração dos maiores tributaristas do Brasil, todos sócios do IBDT foi publicado o segundo "Festschrift" da literatura tributária do Brasil, com 580 páginas $^{5}$

Em 1988, sob a coordenação de Agostinho Toffoli Tavolaro, Brandão Machado e Ives Gandra da Silva Martins saiu o terceiro "Festschrift" com grande colaboração internacional, "Principios Tributários no Direito Brasileiro e Comparado", em homenagem a Gilberto de Ulhôa Canto, e com também acentuada colaboração dos membros da ABDF e do IBDT, totalizando 753 páginas.

Em 1.994, é lançado o quarto "Festschrift" pela editora Resenha Tributária, São Paulo, sob o título "Estudos sobre o Imposto de Renda em memória de Henry Tilbery", homenageando este que foi um dos nossos mais entusiastas participantes e co-fundador não-só da Mesa Semanal de Debates, também integrante do Instituto Brasileiro de Direito Tributário.

Finalmente, em 1998, foi publicado com o apoio do IBDT o quinto "Festschrift", sob o título "Direito Tributário", em homenagem ao tributarista, Brandão Machado, um dos mais dedicados fundadores do IBDT, bem como da Mesa de Debates do IBDT, sob a coordenação de Luis Eduardo Schoueri e Fernando Aurélio Zilvete, editado pela Dialética, São Paulo, com 303 páginas.

Se os "Festschiften" revelam o ápice da elaboração doutrinária e neles estamos contando com grande colaboração dos maiores mestres tanto do Brasil quanto do Exterior é porque podemos ver, com muita alegria, que isto também são resultados dos esforços promovidos pelo IBDT, e colegas, irmanados nos mesmos ideais de "ensino e Justiça da tributação", que é precisamente o emblema de esperança inscrito no escudo do IBDT, entidade complementar à USP. Tudo isto devemos à nossa amada Faculdade, com a qual partilhamos as láureas conquistadas.

São Paulo, julho de 2002.

5. Direito Tributário - Estudos em Homenagem ao Professor Ruy Barbosa Nogueira, Ed.Saraiva, S.Paulo, 1984. 